\title{
A New Method for Determination of Joint Roughness Coefficient of Rock Joints
}

\author{
Shigui Du, Huicai Gao, Yunjin Hu, Man Huang, and Hua Zhao \\ School of Civil Engineering, Shaoxing University, Shaoxing 312000, China \\ Correspondence should be addressed to Huicai Gao; gaohuicai@sina.com \\ Received 31 July 2015; Accepted 22 October 2015 \\ Academic Editor: Fazal M. Mahomed \\ Copyright (C) 2015 Shigui Du et al. This is an open access article distributed under the Creative Commons Attribution License, \\ which permits unrestricted use, distribution, and reproduction in any medium, provided the original work is properly cited.

\begin{abstract}
The joint roughness coefficient (JRC) of rock joints has the characteristic of scale effect. JRC measured on small-size exposed rock joints should be evaluated by JRC scale effect in order to obtain the JRC of actual-scale rock joints, since field rock joints are hardly fully exposed or well saved. Based on the validity analysis of JRC scale effect, concepts of rate of JRC scale effect and effective length of JRC scale effect were proposed. Then, a graphic method for determination of the effective length of JRC scale effect was established. Study results show that the JRC of actual-scale rock joints can be obtained through a fractal model of JRC scale effect according to the statistically measured results of the JRC of small-size partial exposed rock joints and by the selection of fractal dimension of JRC scale effect and the determination of effective length of JRC scale effect.
\end{abstract}

\section{Introduction}

Joint roughness coefficient (JRC) is a vital parameter of the JRC-JCS model for estimation of shear strength of rock joints [1-5]. The JRC will decrease with an increase in sampling length due to JRC scale effect [6-8].

Field investigations show that it is usually hard to measure the JRC of actual-scale rock joints directly because the field rock joints are hardly fully exposed or well saved. The estimation of the JRC of actual-scale rock joints by statistically measured results of the small-scale JRC of partial exposed rock joints is critical to the reliability of the shear strength of rock joints empirically estimated by the JRC-JCS model.

Based on the analysis on quantities of rock joints through joint model test, Barton and Bandis [2] proposed a modified curve of JRC scale effect (see Figure 1) and a modified formula defined as

$$
\mathrm{JRC}_{n} \approx \mathrm{JRC}_{0}\left[\frac{L_{n}}{L_{0}}\right]^{-0.02 J \mathrm{JC}_{0}},
$$

where $\mathrm{JRC}_{n}$ is the JRC value of rock joints with sampling length $L_{n}$ and $\mathrm{JRC}_{0}$ is the JRC value of standard-size joints (the sampling length is $L_{0}$, i.e., $10 \mathrm{~cm}$ ).

$\mathrm{Du}$ et al. [9] have statistically measured the JRC values of 1023 profile curves on SSE group joints from Xiaolangdi by the use of the profilograph and roughness ruler and got the regularity of the decrease characteristic of JRC with an increase in sampling length (see Figure 2).

In this paper, a new method is introduced to study the estimation of the JRC of actual-scale rock joints by statistically measured results of the small-scale JRC of partial exposed rock joints through the analysis of JRC scale effect of rock joints. A fractal model of JRC scale effect was established. The physical meaning of the fractal dimension of JRC scale effect was defined. A method to determine the effective length of JRC scale effect was proposed based on the study of the effectiveness of JRC scale effect.

\section{Fractal Dimension of JRC Scale Effect}

According to (1) and the regularity of JRC scale effect in Figures 1 and 2, the fractal expression of JRC scale effect can be obtained:

$$
\mathrm{JRC}_{n}=\mathrm{JRC}_{0}\left[\frac{L_{n}}{L_{0}}\right]^{-D}
$$

where $D$ is the fractal dimension of JRC scale effect, which defines the velocity rate of $\mathrm{JRC}_{n}$ decreases with an increase in sampling length $L_{n}$. 
TABLE 1: Fractal dimension of JRC scale effect of tonalite joint $J_{1-1}$.

\begin{tabular}{|c|c|c|c|c|c|c|c|}
\hline Direction $^{\circ}{ }^{\circ}$ & $L_{n} / \mathrm{cm}$ & JRC & $D_{n}$ & Direction $/^{\circ}$ & $L_{n} / \mathrm{cm}$ & JRC & $D_{n}$ \\
\hline \multirow{10}{*}{ Trend (0) } & 10 & 10.35 & 0.0000 & \multirow{10}{*}{ Strike (90) } & 10 & 11.90 & 0.0000 \\
\hline & 20 & 8.23 & 0.3307 & & 20 & 7.11 & 0.7431 \\
\hline & 30 & 6.13 & 0.4769 & & 30 & 5.65 & 0.6781 \\
\hline & 40 & 5.20 & 0.4966 & & 40 & 4.75 & 0.6625 \\
\hline & 50 & 4.78 & 0.4800 & & 50 & 4.00 & 0.6774 \\
\hline & 60 & 4.48 & 0.4674 & & 60 & 3.58 & 0.6705 \\
\hline & 70 & 4.58 & 0.4190 & & 70 & 3.38 & 0.6469 \\
\hline & 80 & 4.25 & 0.4281 & & 80 & 3.05 & 0.6598 \\
\hline & 90 & 4.05 & 0.4271 & & 90 & 3.00 & 0.6273 \\
\hline & 100 & 3.78 & 0.4374 & & 100 & 2.80 & 0.6284 \\
\hline \multirow{10}{*}{ Oblique (45) } & 10 & 13.83 & 0.0000 & \multirow{10}{*}{ Oblique (135) } & 10 & 11.10 & 0.0000 \\
\hline & 20 & 7.93 & 0.8025 & & 20 & 7.60 & 0.5465 \\
\hline & 30 & 5.70 & 0.8070 & & 30 & 5.80 & 0.5910 \\
\hline & 40 & 5.15 & 0.7126 & & 40 & 4.65 & 0.6277 \\
\hline & 50 & 4.23 & 0.7360 & & 50 & 4.00 & 0.6341 \\
\hline & 60 & 3.50 & 0.7670 & & 60 & 3.58 & 0.6317 \\
\hline & 70 & 3.23 & 0.7474 & & 70 & 3.30 & 0.6234 \\
\hline & 80 & 2.88 & 0.7546 & & 80 & 3.28 & 0.5863 \\
\hline & 90 & 3.00 & 0.6957 & & 90 & 2.98 & 0.5986 \\
\hline & 100 & 2.78 & 0.6968 & & 100 & 2.95 & 0.5755 \\
\hline
\end{tabular}

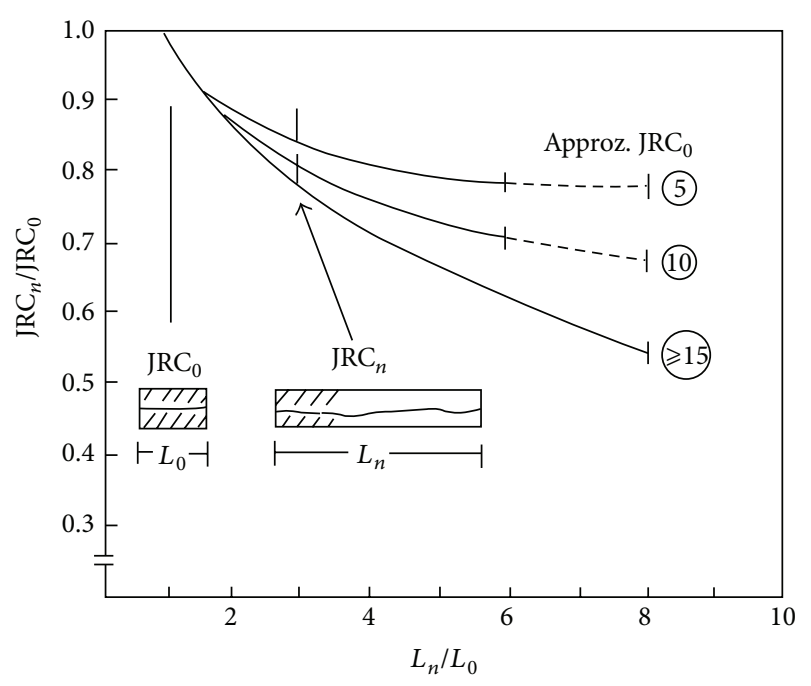

Figure 1: Scale effect related to $\mathrm{JRC}_{0}[2]$.

Statistically measured results show that the fractal dimension of JRC scale effect is comparatively stable. $D_{n}$, calculated from the fractal model of JRC scale effect according to the statistically measured results of $\mathrm{JRC}_{n}$ of random sampling length along the same direction of rock joints in the same wall rock, distributes over a stable interval (see Table 1). From Table 1, it can be seen that the fractal dimension along the tonalite joint $\left(J_{1-1}\right)$ trend direction ranges from 0.3307 to 0.4966 , with mean value of 0.4404 ; the range of fractal dimension along $45^{\circ}$ direction is $0.6957-0.8070$, and mean value is 0.7466 ; the range of fractal dimension along the strike direction is $0.6273-0.7431$, and mean value is 0.6656 ;

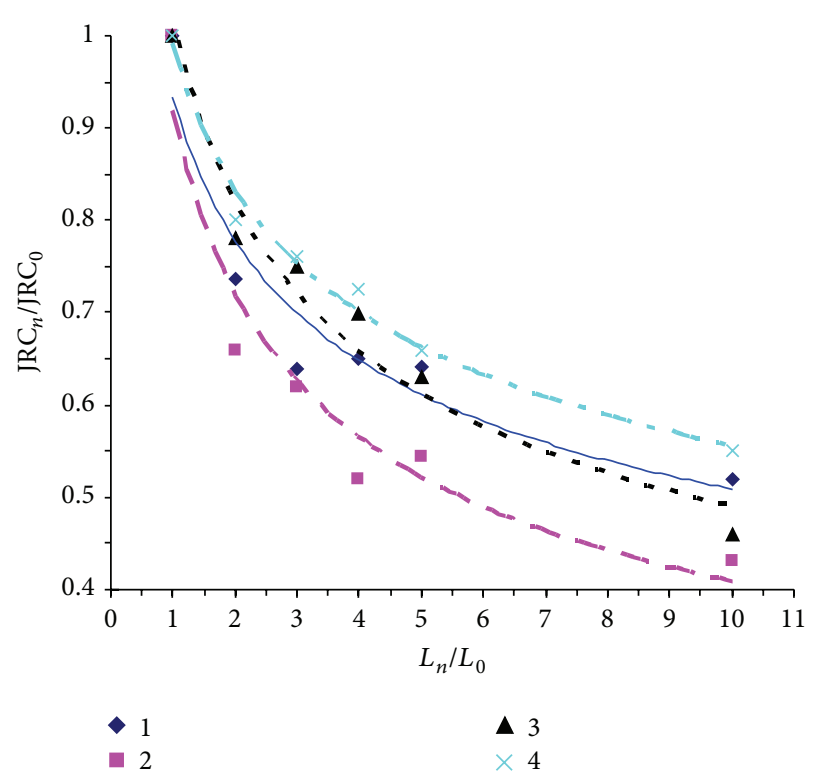

FIGURE 2: JRC scale effect of SSE group joint in Xiaolangdi. (1) Calcareous packsand along joint strike direction $\left(160^{\circ}\right),(2)$ calcareous packsand along joint trend direction $\left(250^{\circ}\right),(3)$ silty clay rock along joint strike direction $\left(160^{\circ}\right)$, and (4) silty clay rock along joint trend direction $\left(250^{\circ}\right)$.

the range of fractal dimension along $135^{\circ}$ direction is $0.5465-$ 0.6341 , and mean value is 0.6016 . This means that the fractal dimension of JRC scale effect $\left(D_{30}\right)$ converted by the JRC measurement results of small-size joint is the same as the fractal dimension of JRC scale effect $\left(D_{100}\right)$ converted by the JRC measurement results of large-size joint. $D_{100}$ and 
TABLE 2: Fractal dimension of JRC scale effect of typical rock joints.

\begin{tabular}{lcc}
\hline Joint wall rock & Joint type & $D_{30}$ \\
\hline Magmatic rock & & \\
Coarse-grained granite & Joint & 0.3458 \\
Fine-grained granite & Joint & 0.3752 \\
Coarse-grained diorite & Joint & 0.3165 \\
Dacite-porphyrite & Joint & 0.3877 \\
Fluorite dike rock & Joint & 0.3500 \\
Basalt & Joint & 0.4883 \\
Sedimentary rock & & \\
Rudaceous grit & Joint & 0.2578 \\
Arkosic sandstone & Joint & 0.1698 \\
Siltstone & Ripple bedding & 0.2850 \\
Siltstone & Joint & 0.4234 \\
Calcilutite & Joint & 0.4758 \\
Calcareous packsand & Joint & 0.5093 \\
Nodule clay rock & Joint & 0.2662 \\
Calcareous mudstone & Ripple bedding & 0.3563 \\
Calcareous mudstone & Joint & 0.2578 \\
Volcanic debris rock & & \\
Volcanic breccia & Joint & 0.2746 \\
Fusion tuff & Joint & 0.4234 \\
Crystal tuff & Joint & 0.2788 \\
Metamorphic rock & & \\
Carbonaceous slate & Foliation & 0.2012 \\
Phyllite rock & Phyllite & 0.4150 \\
Plagioclase hornblendite & 0.3500 \\
\hline & &
\end{tabular}

$D_{30}$ signify $100 \mathrm{~mm}$ and $30 \mathrm{~mm}$ joint sample size. Therefore, the fractal dimension of JRC scale effect can be directly determined according to the JRC statistical measurement results of small-size rock joints. In engineering applications, the value of $D_{30}$ is usually used to analyze the JRC scale effect in order to facilitate the statistical measurement of the JRC.

Considering the difference of JRC scale effect of rock joints with different wall rock, fractal dimension of JRC scale effect of typical rock joints was converted by the fractal model of JRC scale effect according to the statistically measured results from $\mathrm{JRC}_{10}$ and $\mathrm{JRC}_{30}$ of 13529 profile curves of 21 different wall rock joints (see Table 2).

\section{Effective Length of JRC Scale Effects}

In order to discuss the effectiveness of JRC scale effect of rock joints, the sensitivity of JRC ${ }_{n}$ on the sampling length $L_{n}$ was analyzed with constant $\mathrm{JRC}_{0}=12.4$ and $D=0.7009$. From Figure 3, it can be seen that when sampling length $L_{n}$ is smaller than a certain value, $\mathrm{JRC}_{n}$ decreases dramatically with an increase in sampling length $L_{n}$, indicating significant JRC scale effect. While the sampling length $L_{n}$ is larger than the certain value, $\mathrm{JRC}_{n}$ decreases very slowly with the increase of sampling length $L_{n}$; that is, the JRC scale effect is insignificant. The sampling length corresponding to shift from significant to insignificant JRC scale effect is named

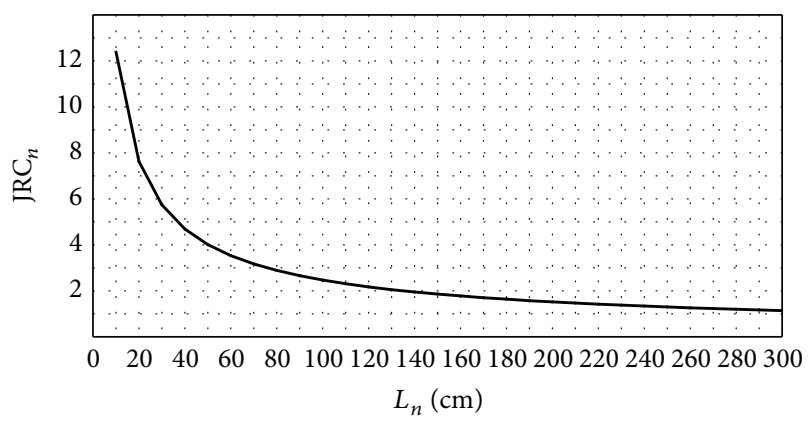

FIGURE 3: Relationship between sampling length $L_{n}$ and $\mathrm{JRC}_{0}$.

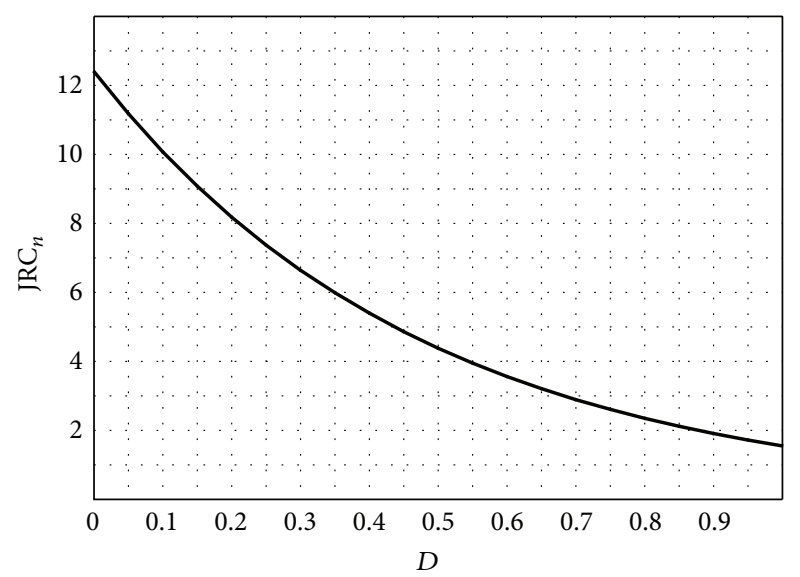

Figure 4: Plot of JRC $n$ versus $D$.

effective length of JRC scale effect, defined as $L_{n}^{*}$. In other words, only within the length of $L_{n}^{*}$ will the influence of JRC scale effect of rock joints be significant.

The sensitivity analysis between $\mathrm{JRC}_{n}$ and fractal dimension of JRC scale effect $D$ is shown in Figure 4 when $\mathrm{JRC}_{0}=$ 12.40 and $L_{n}=80 \mathrm{~cm}$. It can be seen that $\mathrm{JRC}_{n}$ is very sensitive to the value of fractal dimension of JRC scale effect D.

According to the fractal model of JRC scale effect (see (2)), the fractal dimension $D$ can be defined as

$$
D=\frac{\lg \left[\mathrm{JRC}_{n} / \mathrm{JRC}_{0}\right]}{1-\lg \left(L_{n}\right)}
$$

The relationship curve between $D$ and $\lg \left(L_{n}\right)$ calculated by (3) is shown in Figure 5 when $\mathrm{JRC}_{0}=12.40$ and $\mathrm{JRC}_{300}=$ 1.14. From Figure 5, it can be seen that the change of fractal dimension of JRC scale effect is obviously affected by the value of sampling length $L_{n}$ of rock joints.

From the aforesaid analyses, it is clear that the change of fractal dimension of JRC scale effect is very sensitive to JRC and effective length of JRC scale effect, which can be used to determine the effective length of JRC scale effect $L_{n}^{*}$. 
TABLE 3: $D_{30}$ of SSE group joint of Xiaolangdi.

\begin{tabular}{|c|c|c|c|c|c|c|}
\hline \multirow{2}{*}{ Joint wall rock } & \multirow{2}{*}{ Direction } & \multicolumn{2}{|c|}{$L_{n}=10 \mathrm{~cm}$} & \multicolumn{2}{|c|}{$L_{n}=30 \mathrm{~cm}$} & \multirow{2}{*}{$D_{30}$} \\
\hline & & Sample & $\mathrm{JRC}_{10}$ & Sample & $\mathrm{JRC}_{30}$ & \\
\hline \multirow{2}{*}{ Calcareous packsand } & Strike & 35 & 8.61 & 34 & 5.50 & 0.4079 \\
\hline & Trend & 31 & 12.12 & 30 & 7.43 & 0.4454 \\
\hline \multirow{2}{*}{ Calcareous nodule clay rock } & Strike & 88 & 15.83 & 84 & 11.86 & 0.2628 \\
\hline & Trend & 82 & 20.48 & 77 & 15.46 & 0.2560 \\
\hline
\end{tabular}

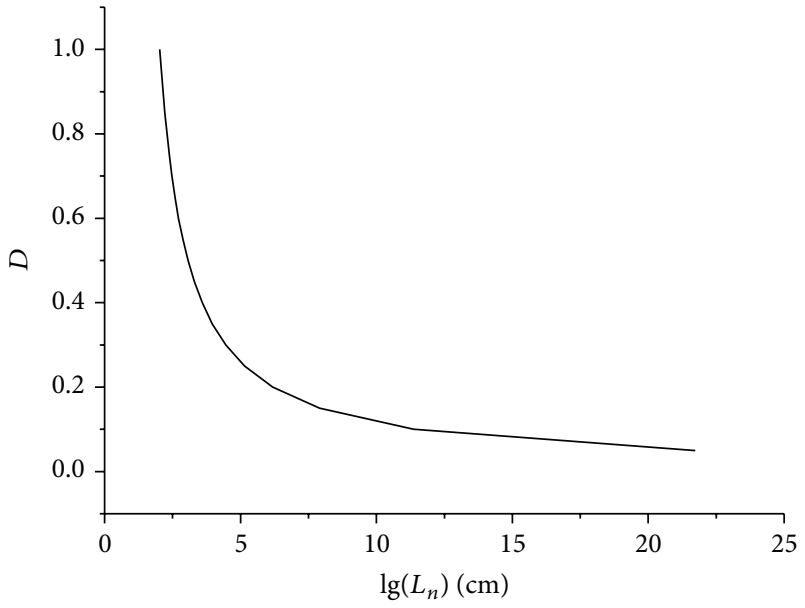

FIGURE 5: Relationship curve of $D-\lg \left(L_{n}\right)$.

\section{Graphic Method for Determination of Effective Length of JRC Scale Effect}

Define $f_{n}$ as the coefficient of JRC scale effect when sampling length is $L_{n}$ :

$$
f_{n}=\frac{\mathrm{JRC}_{n}-\mathrm{JRC}_{n-10}}{L_{n}-L_{n-10}}
$$

where $\mathrm{JRC}_{n}$ is the JRC of rock joints when sampling length is $L_{n} ; \mathrm{JRC}_{n-10}$ is the JRC of rock joints when sampling length is $L_{n-10}, n=20,30,40,50, \ldots$.

Then, the coefficient of JRC scale effect when sampling length is $20 \mathrm{~cm}$ can be expressed as

$$
f_{20}=\frac{\mathrm{JRC}_{20}-\mathrm{JRC}_{10}}{L_{20}-L_{10}}=\frac{\mathrm{JRC}_{20}-\mathrm{JRC}_{0}}{L_{20}-L_{0}} .
$$

Let $f=f_{n} / f_{20}$ as the relative coefficient of JRC scale effect; then

$$
f=\frac{\left(\mathrm{JRC}_{n}-\mathrm{JRC}_{n-10}\right) /\left(L_{n}-L_{n-10}\right)}{\left(\mathrm{JRC}_{20}-\mathrm{JRC}_{0}\right) /\left(L_{n}-L_{0}\right)} .
$$

Substituting (2) into (6) enables (7) to be determined:

$$
f=\frac{\left(0.1 L_{n}\right)^{-D}-\left(0.1 L_{n}-1\right)^{-D}}{2^{-D}-1} .
$$

According to (7), the relationship curve between $L_{n}$ and $f$ can be plotted (see Figure 6). From the figure, it can be found

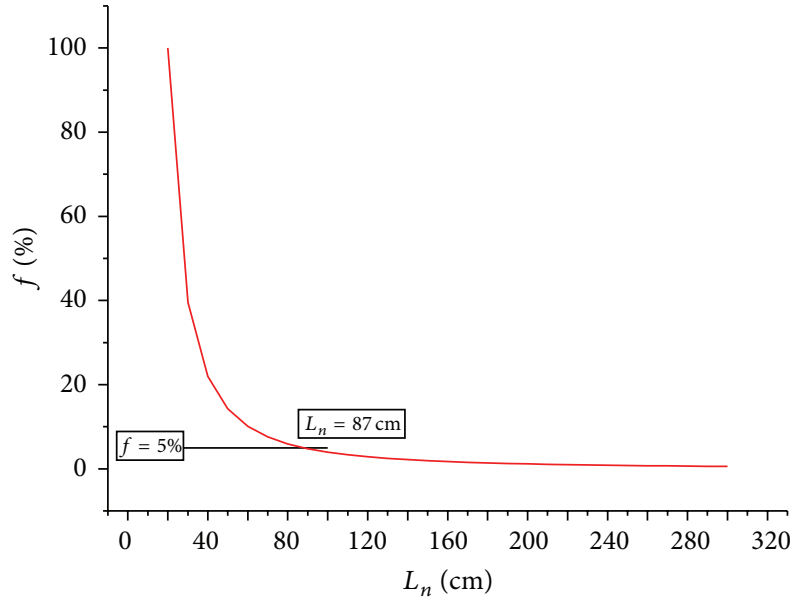

FIgURE 6: Relationship curve of $L_{n}-f$.

that the initial point whereas the relative coefficient of JRC scale effect $f$ starts to increase with the sampling length $L_{n}$ is $f=5 \%$. From error criterion, it can be known that JRC scale effect is insignificant when $f \leq 5 \%$. Then, the value of the effective length of JRC scale effects $L_{n}^{*}$ can be determined.

On the surface of the partial exposed rock joints, $\mathrm{JRC}_{10}$ and $\mathrm{JRC}_{30}$ of profile curves with sampling length of $10 \mathrm{~cm}$ and $30 \mathrm{~cm}$ can be statistically measured. Then, the fractal dimension of JRC scale effect can be calculated by the fractal model of JRC scale effect. Substituting the fractal dimension of JRC scale effect into (7), the relationship curve between $L_{n}$ and $f$ can be obtained (see Figure 6). The sampling length corresponding to $f=5 \%$ on $L_{n}-f$ relationship curve is the effective length of JRC scale effect $L_{n}^{*}$. If the value calculated by the graphic method is between $L_{n}$ and $L_{n+10}$, then let $L_{n}^{*}=L_{n}$ (e.g., $L_{n}^{*}=80 \mathrm{~cm}$ in Figure 6).

Conclusively, the fractal model of JRC scale effect (see (2)) can be used to estimate the JRC of actual-scale rock joints through the statistically measured JRC of small-size rock joints and to determine the fractal dimension of JRC scale effect and the effective length of JRC scale effect.

\section{Case Study}

Statistically measured $\mathrm{JRC}_{10}$ and $\mathrm{JRC}_{30}$ of 387 profile curves of SSE group joint of the west side slope rock of Xiaolangdi reservoir [10] and the values of $D_{30}$ converted by the fractal model of JRC scale effect are listed in Table 3. According 
TABLE 4: JRC of actual-scale SSE group joint of Xiaolangdi.

\begin{tabular}{|c|c|c|c|c|c|}
\hline Joint wall rock & Direction & $\mathrm{JRC}_{0}$ & $L_{n}{ }^{*} / \mathrm{cm}$ & $D_{30}$ & $\mathrm{JRC}_{n}$ \\
\hline \multirow{2}{*}{ Calcareous packsand } & Strike & 8.61 & 120 & 0.4079 & 3.12 \\
\hline & Trend & 12.12 & 110 & 0.4454 & 4.17 \\
\hline \multirow{2}{*}{ Calcareous nodule clay rock } & Strike & 15.83 & 150 & 0.2628 & 7.77 \\
\hline & Trend & 20.48 & 160 & 0.2560 & 10.07 \\
\hline
\end{tabular}

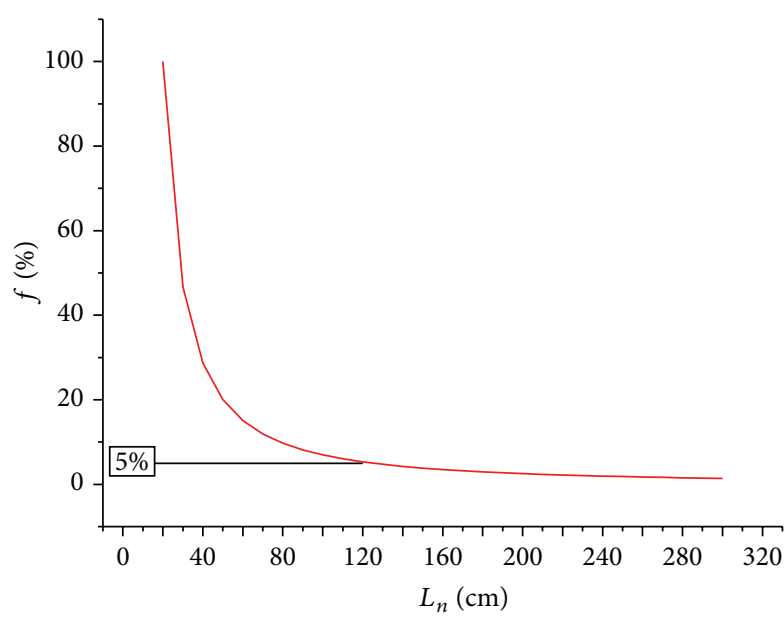

(a)

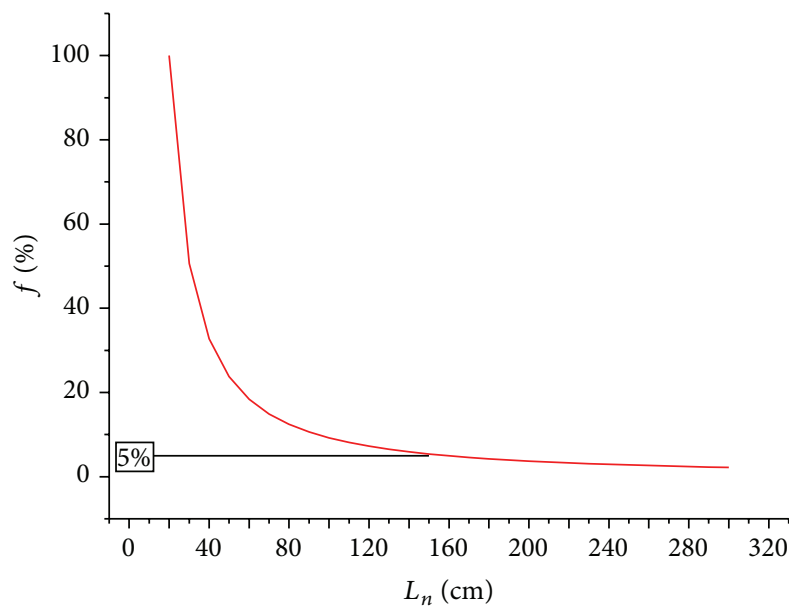

(c)

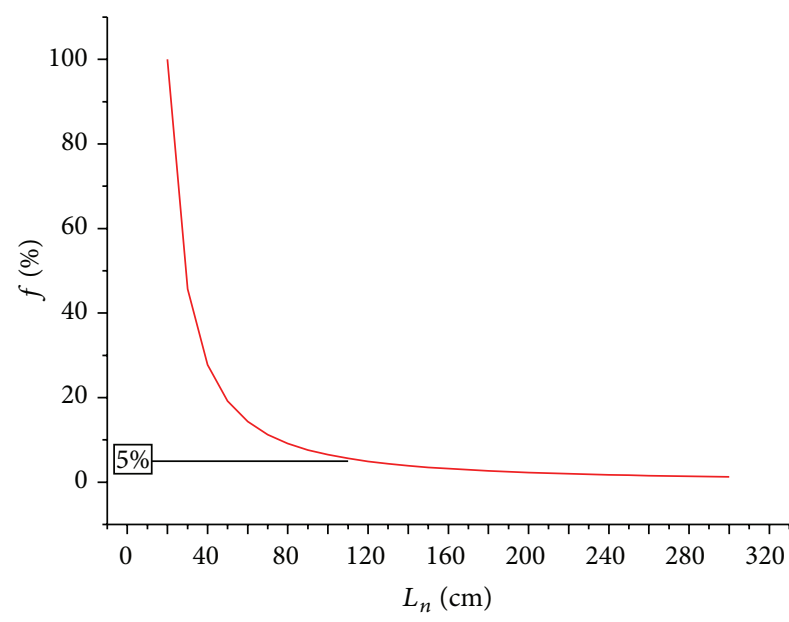

(b)

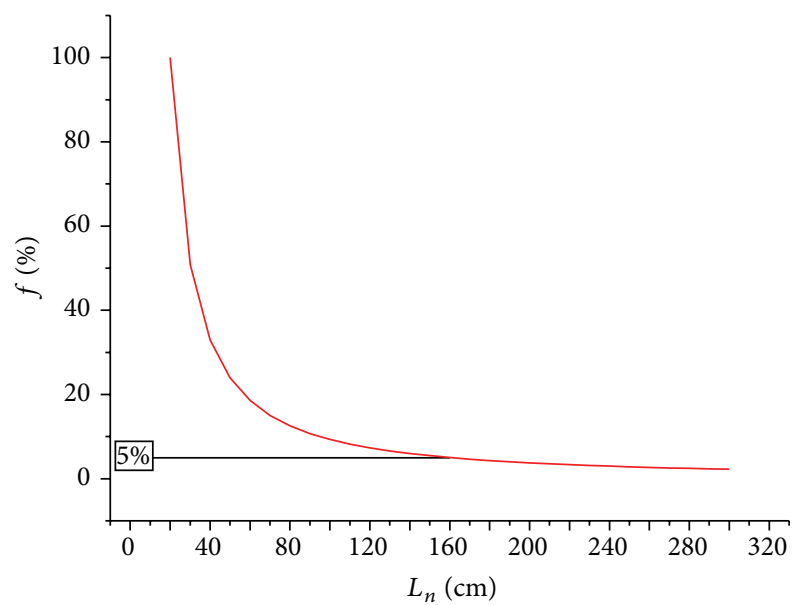

(d)

FIGURE 7: Relationship curves of $L_{n^{-}} f$ of SSE group joint of Xiaolangdi. (a) Calcareous packsand along joint strike direction, (b) calcareous packsand along joint trend direction, (c) calcareous nodule clay rock along joint strike direction, and (d) calcareous nodule clay rock along joint trend direction.

to Table 3, relationship curves of $L_{n^{-}} f$ of calcareous packsand and calcareous nodule clay rock along the joint trend direction and strike direction can be plotted (see Figure 7). From Figure 7, it can be calculated that the effective length of JRC scale effect $L_{n}^{*}$ of calcareous packsand along the joint trend direction and strike direction is $120 \mathrm{~cm}$ and $110 \mathrm{~cm}$, respectively; and the effective length of JRC scale effect $L_{n}^{*}$ of calcareous nodule clay rock along the joint trend direction and strike direction is $150 \mathrm{~cm}$ and $160 \mathrm{~cm}$, respectively. Figure 7 shows that the effective length of JRC scale effect $L_{n}^{*}$ decreases with an increase in the fractal dimension of JRC scale effect.
According to the effective length of JRC scale effect $L_{n}^{*}$ calculated by the graphic method, the actual-scale joint roughness coefficients $\mathrm{JRC}_{n}$ of calcareous packsand and calcareous nodule clay rock along the joint trend direction and strike direction estimated by the fractal model of JRC scale effect are listed in Table $4 . \mathrm{JRC}_{n}$ in Table 4 is used in the empirical estimation of shear strength with the JRCJCS model, which contains the scale effect and has wide application (because the JRC is obtained by directional statistical measurement). Thus, the joint shear strength parameters obtained by empirical estimation can be directly used to evaluate the stability of the rock. 


\section{Conclusions}

Hence, our conclusions are as follows:

(1) Joint roughness coefficient of rock joints has the characteristic of scale effect. The sensitivity analysis of $\mathrm{JRC}_{n}$ to the sampling length $L_{n}$ shows that $\mathrm{JRC}_{n}$ decreases dramatically with an increase in sampling length $L_{n}$ when the sampling length $L_{n}$ is smaller than a certain value; when the sampling length $L_{n}$ is larger than the certain value, $\mathrm{JRC}_{n}$ decreases very slowly with an increase in sampling length $L_{n}$. This eigenvalue of JRC scale effect is named the effective length of JRC scale effect. Only within the length of $L_{n}^{*}$ will the influence of JRC scale effect be significant. The sensitivity analysis of the relative coefficient of JRC scale effect $f$ to the sampling length $L_{n}$ shows that the sampling length corresponding to $f=5 \%$ of $L_{n}-f$ relationship curve is the effective length of JRC scale effect, $L_{n}^{*}$.

(2) The sensitivity analysis of the fractal dimension of JRC scale effect $D$ to the sampling length $L_{n}$ shows that the change of $D$ strongly affects the value of $L_{n}$. Therefore, the fractal dimension of JRC scale effect can be used to determine the effective length of JRC scale effect, $L_{n}^{*}$. The case study shows that the effective length of JRC scale effect $L_{n}^{*}$ decreases with an increase in the fractal dimension of JRC scale effect.

(3) The procedures of the graphic method to determine the effective length of JRC scale effect are as follows. Firstly, $\mathrm{JRC}_{10}$ and $\mathrm{JRC}_{30}$ are measured through the statistically measured profile curves with sampling length of $10 \mathrm{~cm}$ and $30 \mathrm{~cm}$ on the surface of rock joints. Secondly, the fractal dimension of JRC scale effects $D_{30}$ is determined by the fractal model of JRC scale effect. Thirdly, substituting the fractal dimension into the relative coefficient of JRC scale effect formula (see (7)), the relationship curve of $L_{n^{-}} f$ can be plotted. Finally, the sampling length corresponding to $f=5 \%$ in $L_{n^{-}} f$ relationship curve is the effective length of JRC scale effect, $L_{n}^{*}$ (if the value calculated by graphic method is between $L_{n}$ and $L_{n+10}$, then let $\left.L_{n}^{*}=L_{n}\right)$.

(4) Field investigations show that the field rock joints are hardly fully exposed or well saved. The graphic method in some terms solves the problem by promoting the utilization of the fractal model of JRC scale effect. Using this method, the JRC of actual-scale rock joints can be determined by the fractal model of JRC scale effects through the statistically measured JRC of small-size and partial exposed rock joints.

\section{Conflict of Interests}

The authors declare that there is no conflict of interests regarding the publication of this paper.

\section{Acknowledgments}

This study was supported by the National Natural Science Foundation of China (no. 41427802, no. 51279177, and no. 41302257) and the Natural Science Foundation of Zhejiang Province (no. LZ13D020001, no. LQ13D020001).

\section{References}

[1] N. Barton, "Review of a new shear-strength criterion for rock joints," Engineering Geology, vol. 7, no. 4, pp. 287-332, 1973.

[2] N. Barton and S. Bandis, "Review of predictive capability of JRC-JCS model in engineering practice," in Proceedings of the International Symposium on Rock Joints, pp. 603-610, A.A. Balkema Publishers, Loen, Norway, June 1990.

[3] Y. J. Jiang, B. Li, and Y. Tanabashi, "Estimating the relation between surface roughness and mechanical properties of rock joints," International Journal of Rock Mechanics and Mining Sciences, vol. 43, no. 6, pp. 837-846, 2006.

[4] S.-W. Lee, E.-S. Hong, S.-I. Bae, and I.-M. Lee, "Modelling of rock joint shear strength using surface roughness parameter, Rs," Tunnelling and Underground Space Technology, vol. 21, no. 3-4, pp. 239-247, 2006.

[5] S. G. Du, Y. J. Hu, X. F. Hu, and X. Guo, "Comparison between empirical estimation by JRC-JCS model and direct shear test for joint shear strength," Journal of Earth Science, vol. 22, no. 3, pp. 411-420, 2011.

[6] J. P. Seidel and C. M. Haberfield, "Towards an understanding of joint roughness," Rock Mechanics and Rock Engineering, vol. 28, no. 2, pp. 69-92, 1995.

[7] N. Fardin, O. Stephansson, and L. Jing, "The scale dependence of rock joint surface roughness," International Journal of Rock Mechanics and Mining Sciences, vol. 38, no. 5, pp. 659-669, 2001.

[8] M. MŁynarczuk, "Description and classification of rock surfaces by means of laser profilometry and mathematical morphology," International Journal of Rock Mechanics and Mining Sciences, vol. 47, no. 1, pp. 138-149, 2010.

[9] S. Du, Y. Hu, and X. Hu, "Measurement of joint roughness coefficient by using profilograph and roughness ruler," Journal of Earth Science, vol. 20, no. 5, pp. 890-896, 2009.

[10] S. G. Du and B. T. Pan, Engineering Geology of Rock Slope of Xiao Lang Di, Seismic Press, Beijing, China, 1998 (Chinese). 


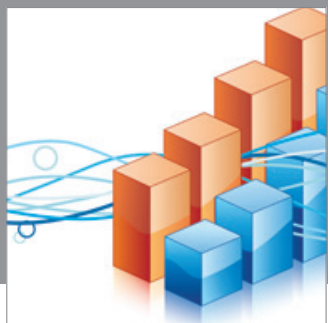

Advances in

Operations Research

mansans

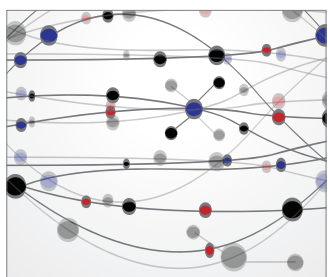

The Scientific World Journal
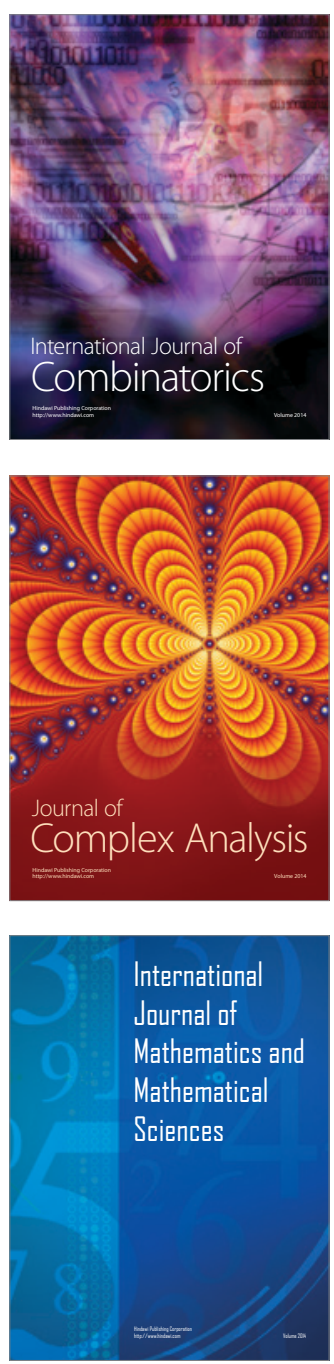
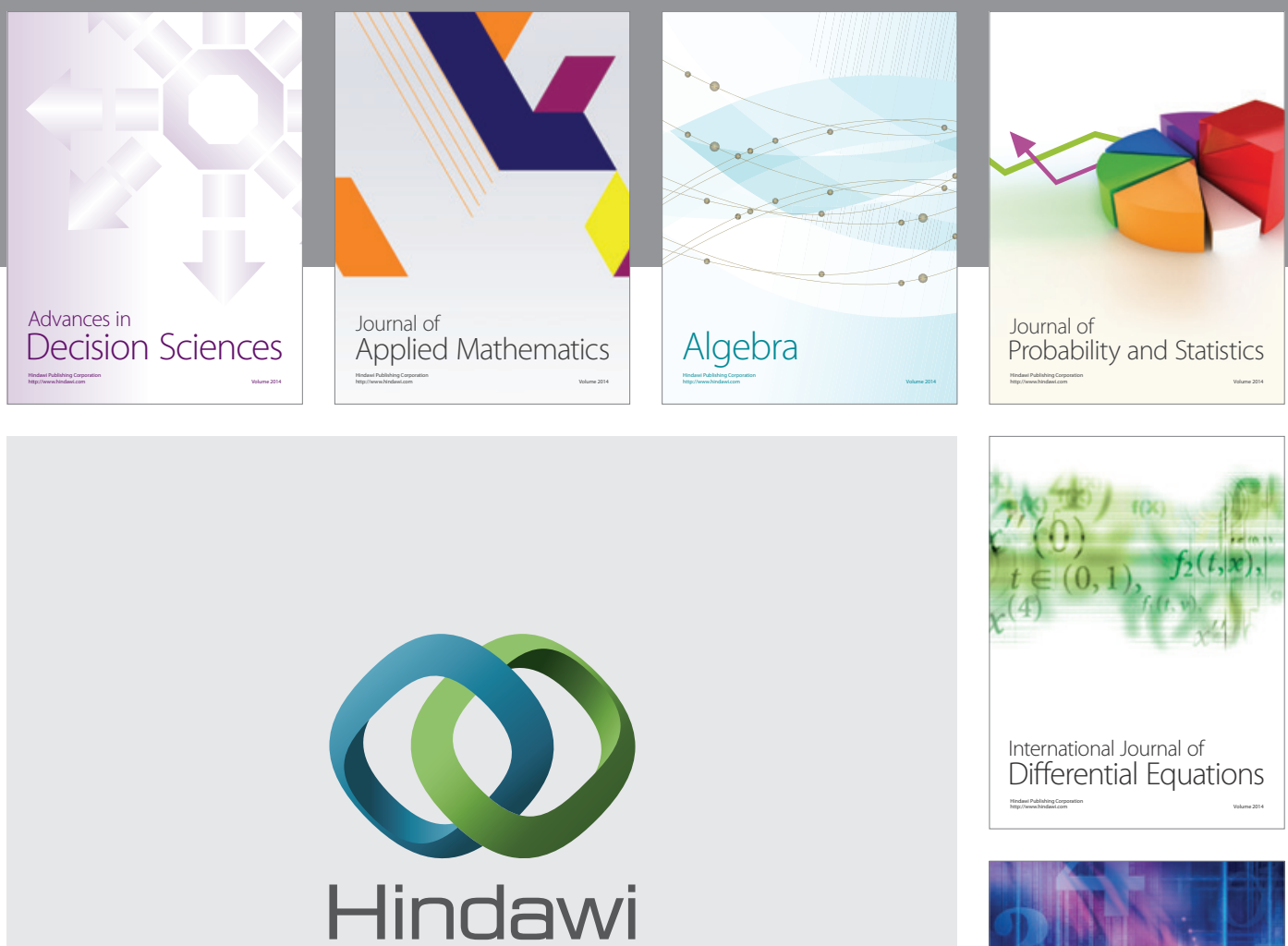

Submit your manuscripts at http://www.hindawi.com
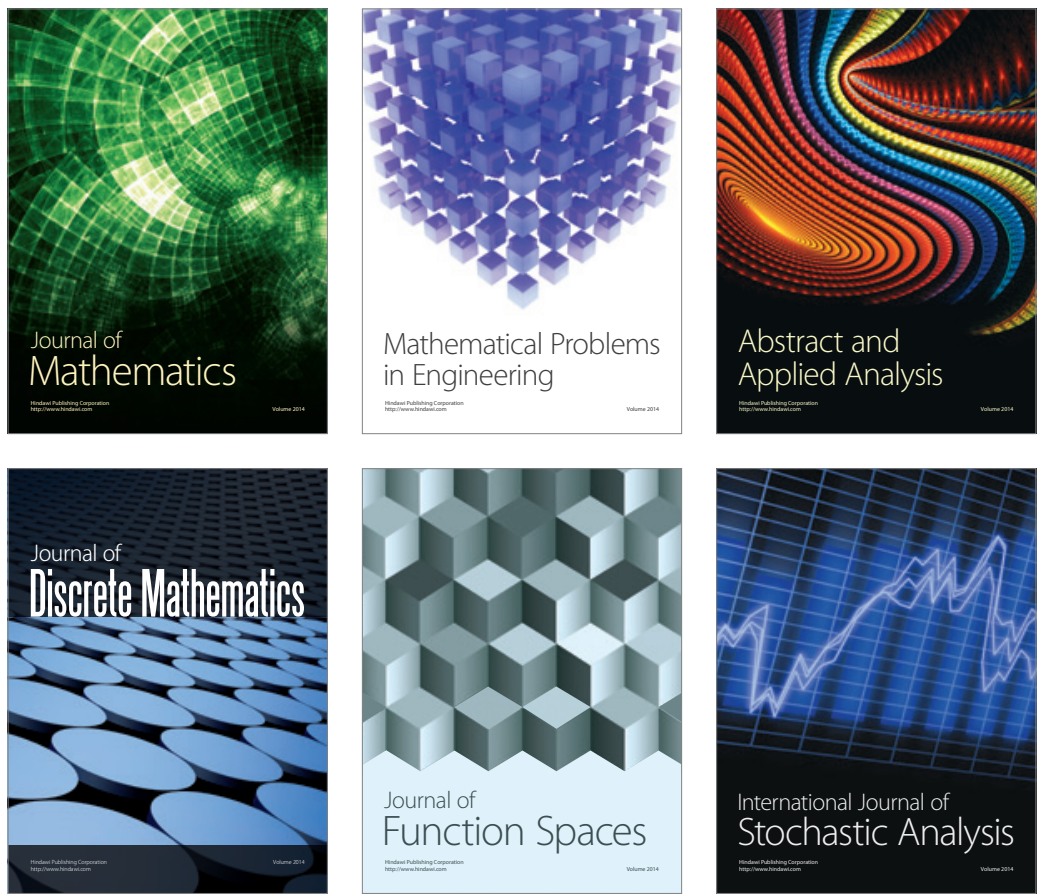

Journal of

Function Spaces

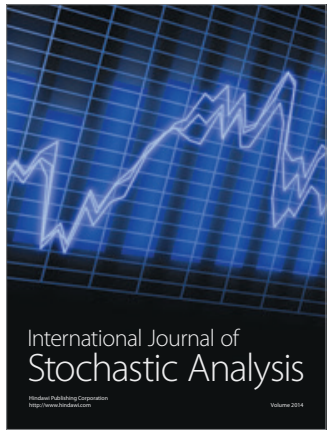

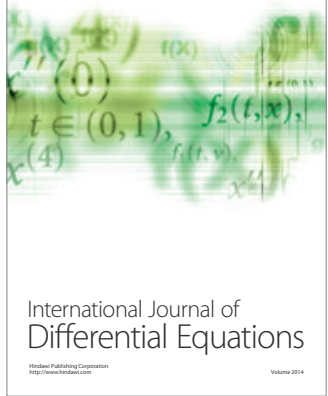
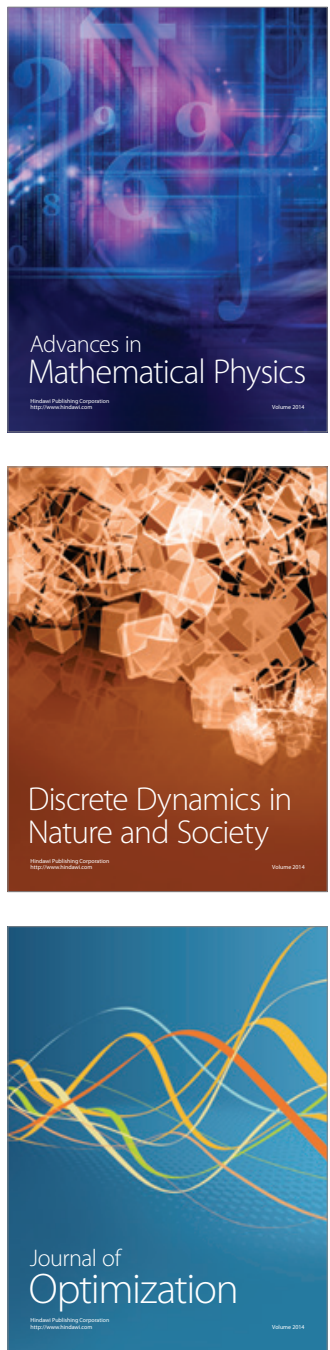